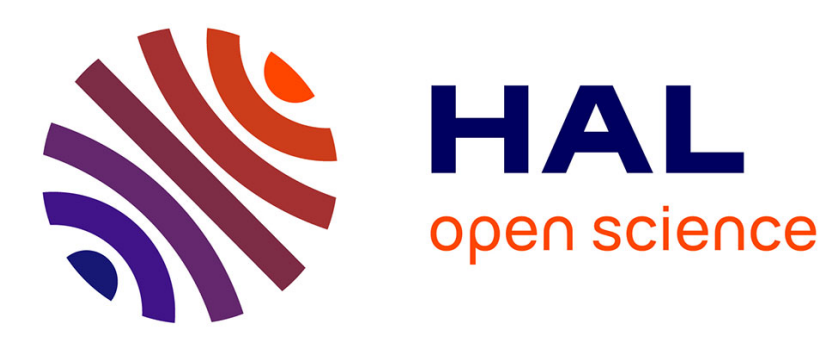

\title{
Aspects for Better Understanding of Engineering Changes in Shipbuilding Projects: In-Depth Case Study
}

\author{
Natalia Iakymenko, Marco Semini, Jan Ola Strandhagen
}

\section{To cite this version:}

Natalia Iakymenko, Marco Semini, Jan Ola Strandhagen. Aspects for Better Understanding of Engineering Changes in Shipbuilding Projects: In-Depth Case Study. IFIP International Conference on Advances in Production Management Systems (APMS), Sep 2019, Austin, TX, United States. pp.588-595, 10.1007/978-3-030-30000-5_72 . hal-02419210

\section{HAL Id: hal-02419210 \\ https://hal.inria.fr/hal-02419210}

Submitted on 19 Dec 2019

HAL is a multi-disciplinary open access archive for the deposit and dissemination of scientific research documents, whether they are published or not. The documents may come from teaching and research institutions in France or abroad, or from public or private research centers.
L'archive ouverte pluridisciplinaire HAL, est destinée au dépôt et à la diffusion de documents scientifiques de niveau recherche, publiés ou non, émanant des établissements d'enseignement et de recherche français ou étrangers, des laboratoires publics ou privés. 


\title{
Aspects for better understanding of engineering changes in shipbuilding projects: in-depth case study
}

\author{
Natalia Iakymenko ${ }^{[0000-0001-8407-8785]}$, Marco Semini and Jan Ola Strandhagen \\ NTNU, MTP Valgrinda, S.P.Andersens vei 3, 7031, Trondheim, Norway \\ natalia.iakymenko@ntnu.no, marco.semini@ntnu.no, \\ ola.strandhagen@ntnu.no
}

\begin{abstract}
Engineering changes are driving forces of product development and improvement in any company. In shipbuilding projects, engineering changes are introduced throughout the project duration and cannot be planned or introduced to the next production run since products are only made once and never repeated. A lot of research exists on engineering changes and their management in general, but the focus of this study is to increase the awareness and understanding of the engineering changes specifically in shipbuilding projects. In this study, an in-depth investigation of engineering changes and aspects having influence on engineering change implementation performance in Norwegian shipbuilding company was performed. The findings indicate that engineering changes and their implementation performance are related to such aspects as market segment, supply chain network, design maturity, overlapping project stages, and timing of EC occurrence in the project. These aspects, their influence on the number of ECs, and EC implementation and performance, are described and analyzed in the paper, and future research plans are presented.
\end{abstract}

Keywords: engineering change, shipbuilding, engineer-to-order, case study.

\section{$1 \quad$ Introduction}

There is a fair share of standardized shipbuilding in the world, but European, and particularly Norwegian shipbuilding industry, is still producing highly customized products in short series, or even volumes of one. Their products are designed and built as separate projects. Typical strategy for this production environment is engineer-toorder [1]. Engineering changes (ECs) are common and unavoidable in this production environment [2]. As opposed to make-to-stock environment, where ECs are batched and implemented before the start of production, ETO companies have to be able to implement changes at any stage of the project duration [3]. In this study ECs are defined as modifications to structure, behavior and function of a technical artefact that has already been released during the design process [2, 4]. Even though ECs are implemented in order to improve the product or adapt it to the new requirements and needs, they often result in project cost overruns and delays [4]. Extensive amount of the literature suggests strategies, practices and tools for improved management of ECs. However, different contextual conditions of production environments and indus- 
tries are not always explicitly staged in the studies. Hence, the aim of this paper is to investigate what aspects have moderating effects on EC implementation process, cost and time of ECs, as well as number of occurring ECs, in shipbuilding companies.

The paper begins by presenting a brief theoretical background in section 2 . Section 3 outlines a research methodology used in this study. In section 4, case company is introduced, followed by the case study findings in section 5. Section 6 concludes the paper and describes further research agenda.

\section{Theoretical background and research motivation}

There is a vast amount of research dedicated to ECs and their management. It is outside of the scope of this paper to provide overview of all the ECM strategies, practices and tools available in the literature. Those interested might refer to the most comprehensive literature review on ECM conducted by Hamraz et al. (2013) [2] and further continued and complemented by Ullah et al. (2016) [5]. In addition to that, studies conducted by Huang et al. (2003) [6] and Storbjerg et al. (2016) [7] provide excellent overviews of ECM strategies, practices and tools. The authors of this paper conducted a literature study on this topic as well and identified that is seems that research on ECs up to date has concentrated heavily in the engineering design domain and there is almost no research studying influence of ECs on production, logistics, and supply chain and vice versa. Exceptions are such studies as Wänström et al. (2006) [8], Ho (1994) [9], and Lin and Zhou (2011) [10]. In addition to that, most studies on ECs still do not differentiate between the different production environments, even though back in 2009 Eckert et al. [11] suggested that future ECM practices and tools should be developed considering such factors as production volume, the degree of customer involvement in customization, the degree of internal and external uncertainty, and the inherent product complexity.

This study explores if these research gaps are worth studying; are there moderating aspects of the specific production environment that differentiate it from other environments when it comes to ECs and their management? How do these aspects affect EC implementation performance? This study goes outside the design domain to explore production, logistics and supply chain aspects of EC implementation.

\section{$3 \quad$ Research methodology}

In Fig. 1, the basic research framework is outlined, which shows the relationships between the studied constructs. When EC occurs, it is analyzed and implemented using engineering change management (ECM) processes, procedures, and tools. ECs come at a cost of course; money and resources are spent on their implementation. This study hypothesizes that both number of occurring ECs, how they are managed, and cost and time of their implementation will be influenced by the moderating aspects specific for the shipbuilding environment. No specific hypotheses as to exact relationships between these aspects and EC implementation were formulated prior to conducting the study. Therefore, an inductive research approach was chosen [12]. In- 
depth case study in Norwegian shipbuilding company was conducted. The case study method was chosen because of its suitability for theoretical development, where constructs are not defined or only partially defined $[13,14]$. In addition to that, case study method allows for a more comprehensive understanding of the nature and complexity of a phenomenon studied $[13,14]$. This paper presents part of the findings from the performed case study.

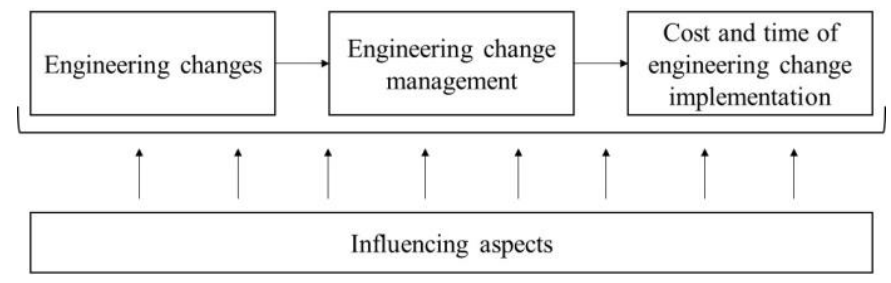

Fig. 1. Research framework

The data was collected over three years' time span and several visits to the case company, ranging from 1 to 5 days in duration. Several meetings and semi-structured interviews were conducted with deputy CEO, deputy managing director, business analysts, project managers, design and engineering managers, and production planners. The interviews consisted of two stages. At a first stage, ECM processes in the case company were mapped and ECM practices and tools used by the company were identified. At the second stage, interviewer went through the whole ECM process with the interview participants and asked what aspects were contributing to the way ECs are managed at each stage of the process, the number of occurring ECs, and finally their cost and time of implementation. Since no data on exact EC implementation time and cost is available in the company, qualitative measurement was used, interview participants were asked to describe the degree of a given aspect's effect on EC implementation performance. In addition, documents related to ECs were collected, including descriptions of EC management procedures, change evaluation sheets, company presentations, publicly available information, and reports on the previous research projects conducted with the case company by the research group.

For data analysis, recommendations of Eisenhardt [14], and Miles, Huberman and Saldana [15] were followed. The NVivo software was used to store, transcribe, code and analyze the data. First, interviews were transcribed, and a narrative description of the case history was created, ECM processes were described, ECM practices and tools were identified. After that, a two-stage coding was performed. At the first stage, descriptive codes were assigned to data chunks to detect reoccurring patters in all interviews and the documents available in an inductive way. From this, at the second stage of coding, similar codes were clustered together to create a smaller number of categories (pattern codes). The results of the coding were tabulated to compare findings across different interviews. The researchers iterated repeatedly between the data and emergent theory until a strong match between theory and data was reached. Several 
main aspects were identified, but due to the limited length of the paper, only five (most mentioned by the interview participants) aspects are presented.

\section{$4 \quad$ Case study}

The study was conducted in a Norwegian shipbuilding company (further called "N"). Typical shipbuilding project consists of following stages: design (concept, contract and basic), engineering, production, procurement, commissioning, and after-sale [3]. $\mathrm{N}$ performs several roles in shipbuilding industry, both as a ship designer, a shipyard, and a main equipment supplier. $\mathrm{N}$ is a part of global shipbuilding supply chain. This supply chain generally consists of four main actors: ship designer, shipyard, main equipment suppliers and shipowner (customer). In addition to that, classification organizations are involved; they establish and check technical standards for the construction and operations of ships. A simplified N's supply chain is presented in Figure 2 .

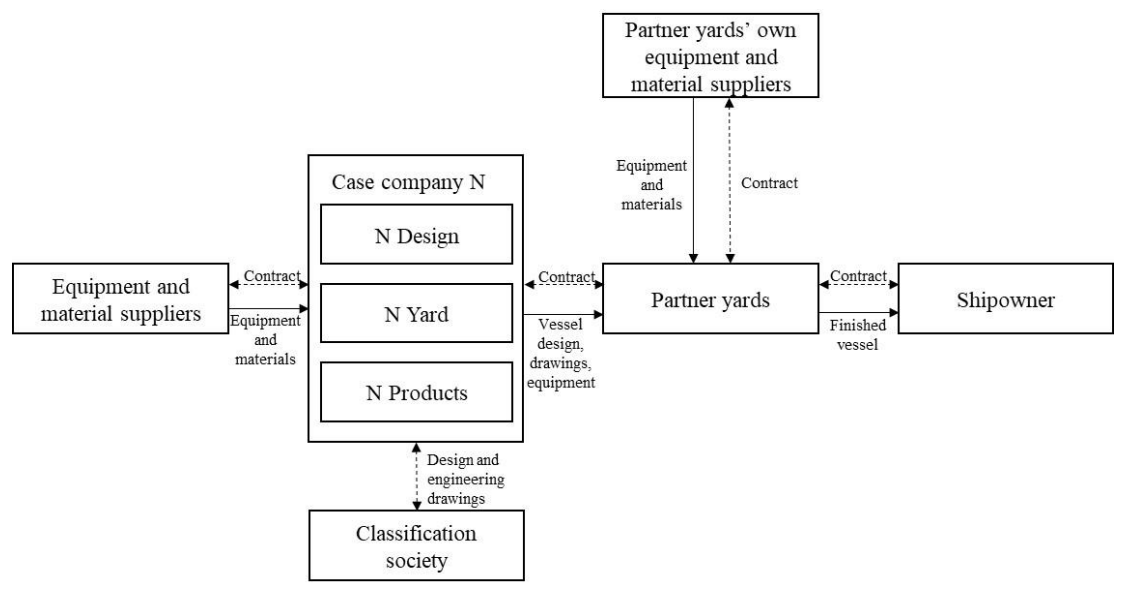

Fig. 2. Shipbuilding supply chain

First, N Design and ship owner develop and negotiate on vessel details. $\mathrm{N}$ designs vessels and delivers design to the own yard or sells to the external yard, depending on the customer preferences. Contractual relationships are established between the shipowner and the yard, meaning there are no contractual relationships between the designer and the shipowner. Detailed engineering is performed by the engineering team at the yard. Even though partner yards buy designs from $\mathrm{N}$ and carry contractual responsibility for delivering the vessel to the shipowner, both the designer and the yard share responsibility since the customer will receive a vessel with the designing company's brand name on it. Most often ship designer coordinates the engineering and procurement of the main equipment, however sometimes this equipment is procured by the yard or customer. In this case, designer does not have a direct contact with suppliers. In cases when the vessel is built in $\mathrm{N}$ yard, the hull is produced at external yards to cut shipbuilding costs. After the hull is towed to $\mathrm{N}$ yard, it is outfitted with 
main equipment, pipes, cabling, and HVAC in the dry dock. After that, the vessel is moved outside the dock, where final outfitting is done on the water. Procurement (especially procurement of main equipment) and production usually starts before the engineering is finished, which, according to the company, shortens project duration by up to 12 months. Project delivery time is around 2 years.

\section{Aspects affecting EC implementation in shipbuilding projects}

In this chapter, we provide five aspects that affect ECs and their implementation in the case company with some real-life examples.

(1) Market segment. For a long time, main case company's specialty was building offshore support vessels (OSVs), but they have recently moved into a new market segment - cruise vessels. Here, professional culture, new standards, rules and regulations, and experience of the company were mentioned as three closely related aspects affecting ECs and their implementation in the company.

Professional culture. Customers in OSV market were local, they had long relationships with $\mathrm{N}$ based on mutual trust. All issues related to ECs were resolved by making phone calls. New customers, however, are much more formal and stricter in their approach. Each issue is thoroughly checked against specifications and standards. Consequently, it takes much longer time to agree on who carries monetary responsibility for the change implementation. This is further complicated by the fact that $\mathrm{N}$ must work with new specifications, rules and regulations for cruise vessels. Often, something that was not an issue for OSVs appears an issue for the cruise vessel. This increases the number of ECs, which $\mathrm{N}$ is not able to predict in advance and must take full responsibility for. Ability to detect such potential issues in OSV market was based on the experience of the company, which still needs to be developed for the cruise vessels.

(2) Supply chain network. $\mathrm{N}$ operates in a global supply chain, where either design, engineering or production are often performed by external actors. Here, following aspects are affecting ECs: coordination of ECs across multiple companies, and competence and experience of external actors.

Coordination of ECs across multiple companies. In shipbuilding projects design, engineering or production are often performed by separate companies. ECs in this situation result in higher number of iterations between the companies and longer EC implementation time. For example, if an EC propagates from the shipyard to one of the suppliers, receiving input from this supplier can be a bottleneck. The time for supplier to give the necessary information might be even longer if the design and engineering do not have a direct contact with the supplier. For example, in one of the projects several changes affecting the whole design of the vessel (i.e. stability, power supply, etc.) occurred. To update design drawings, $\mathrm{N}$ needed updated technical specifications from several suppliers (i.e. engine supplier). However, $\mathrm{N}$ was not able to contact them directly since it was external shipyard, not $\mathrm{N}$, who had contracts with these suppliers. Hence, $\mathrm{N}$ had to resolve all issues by contacting the shipyard first, 
who in turn contacted the suppliers. This considerably increased EC processing time and led to project delays.

Competence and experience of external actors. $\mathrm{N}$ yard is able to cope with some minor design and engineering changes without necessarily involving the design and engineering departments. The yard is able to fix the issues and predict possible propagations of such change. External yards are often do not have such experience and the production often must be stopped to resolve occurred problems. For example, when building one of the offshore support vessels in a Chinese shipyard, a lot of problems with cargo system occurred, which could have been solved by the production stuff if the vessel would have been built locally. However, in case of a Chinese shipyard, production had to be stopped, drawings updated by $\mathrm{N}$ and translated into Chinese, which took additional several weeks of work.

(3) Design maturity affects both the number of ECs, and EC assessment and implementation. Projects with low levels of design maturity (e.g. maturity of the whole product or separate systems and parts) usually generates more changes in the downstream stages of the project. In addition to that, implementation of new technology makes it difficult to predict possible EC propagations to other systems of the vessel. For example, when building platform supply vessel, new exhaust system was introduced. The issue of back pressure on bending pipes was not immediately understood, which led to rework (rearranging pipes) at the production stage. Such propagations are very hard to detect, and they will typically be noticed at a later and more costly project stages; as noted by the interview respondents, cost of implementing EC in shipbuilding projects increases tenfold with each subsequent stage of the project.

(4) Overlapping design, engineering, procurement and production stages implies that instead of performing these activities sequentially, each activity starts before the previous is finished. By doing this, products are produced in less time. $\mathrm{N}$ follows this approach. However, this approach also implies that there should be design freezes at the design and engineering stages, after which changes are not allowed. However, the shipowner might want to introduce changes at any stage of the project. In this situation ECs affect a bigger number of activities and increases needed coordination efforts. For example, more ECs need to be handled by involving production stage because engineering was not finished before the start of production and incomplete drawings were shared between the project actors.

(5) Timing of EC occurrence. As it was already mentioned, the cost of an EC implementation in shipbuilding projects increases tenfold with each subsequent stage of the project. Early ECs, before procurement and production has started, are resolved by engineering and only include administrative costs of changing the drawings. However, when moving into procurement and production, ECs lead to rework, demolition and scrap of already produced components. This finding is in line with the Rule of Ten, stating that the cost of ECs increases exponentially with each stage of the project, and hence late ECs should be avoided [16]. In addition to that, there are specific cost drivers appearing at different stages of shipbuilding process. The shipbuilding process consists of following stages: part production, block building, block outfitting, block (hull) assembly, dock outfitting and quay outfitting. For example, when moving from block building to block outfitting, following cost drivers will appear, such as 
reduced accessibility (workers need to operate in narrow spaces), higher risk of damage of already installed parts (some parts need to be covered and protected in case of rework). When moving from block outfitting to assembly, in addition to accessibility and risk of damage, following aspects need to be considered: crowdedness or stacking of trades (several production disciplines working in the same area, which leads to productivity decrease), vertical transportation and long distances to the place of work, work position (not possible to turn sections around). At the quay outfitting, all the spaces are closed, there is no roof in case of bad weather conditions (especially expensive for paint work), fewer available cranes. There additional production specifics of different types of vessels. For example, cruise vessels have 2-3 times more decks, which drastically increases travelling time for the workers.

All the above-mentioned aspects are not easily quantifiable, but they are important to understand and consider when implementing ECs in shipbuilding projects.

\section{Conclusions and further research}

This study had provided insights into some aspects affecting ECs and their implementation in shipbuilding projects. First, this study has showed that there are specific aspects of the shipbuilding industry that influence ECs, their management and implementation performance. Specifically, the study showed that entering into a new market segment, low competence and experience of actors in shipbuilding supply chain network, and a low maturity of the design increases the number of ECs at different stages of shipbuilding projects. Supply chain actors' experience and design maturity increase the chance of unpredicted EC propagations. Furthermore, different professional culture of the customers, global distributed supply chain network, competence of supply chain actors, design maturity, overlapping of project stages, and timing of EC occurrence are the aspects that contribute to EC implementation cost and time. These aspects should be taken into consideration by the researchers when working on ECM practices and tools. Future research should perform in-depth analysis of ECs in several shipbuilding (or ETO) projects to determine all the aspects contributing to EC implementation performance. A new approach for EC assessment that goes outside engineering design domain should and takes into consideration such aspects.

It is expected that this paper can support practitioners in making sense of ECs in complex shipbuilding projects. However, the results should be handled with care since, like any other single case study, this paper has its limitations in terms of external validity and generalizability.

\section{$7 \quad$ References}

1. Zennaro, I., Finco, S., Battini, D., and Persona, A.: Big size highly customised product manufacturing systems: a literature review and future research agenda. International Journal of Production Research, pp. 1-24 (2019). 
2. Hamraz, B., Caldwell, N., and Clarkson, P.: A holistic categorization framework for literature on engineering change management. Systems Engineering 16(4), pp. 473-505 (2013).

3. Semini, M., Haartveit, D.E.G., Alfnes, E., Arica, E., Brett, P.O., and Strandhagen, J.O.: Strategies for customized shipbuilding with different customer order decoupling points. Proceedings of the Institution of Mechanical Engineers, Part M: Journal of Engineering for the Maritime Environment (2014).

4. Jarratt, T., Clarkson, J., and Eckert, C.: Engineering change. Design process improvement, pp. 262-285 (2005).

5. Ullah, I., Tang, D., and Yin, L.: Engineering product and process design changes: a literature overview. In 9th International Conference on Digital Enterprise Technology - DET 2016.2016.pp. 25-33.

6. Huang, G.Q., Yee, W.Y., and Mak, K.L.: Current practice of engineering change management in Hong Kong manufacturing industries. Journal of Materials Processing Technology 139(1), pp. $481-487$ (2003).

7. Storbjerg, S.H., Brunoe, T.D., and Nielsen, K.: Towards an engineering change management maturity grid. Journal of Engineering Design 27(4-6), pp. 361-389 (2016).

8. Wänström, C., Lind, F., and Wintertidh, O.: Creating a model to facilitate the allocation of materials planning resources in engineering change situations. International journal of production research 44(18-19), pp. 3775-3796 (2006).

9. Ho, C.J.: Evaluating the impact of frequent engineering changes on MRP system performance. The International Journal of Production Research 32(3), pp. 619-641 (1994).

10. Lin, Y. and Zhou, L.: The impacts of product design changes on supply chain risk: a case study. International Journal of Physical Distribution \& Logistics Management 41(2), pp. 162-186 (2011).

11. Eckert, C., Clarkson, J., de Weck, O., and Keller, R.: Engineering change: drivers, sources, and approaches in industry. In Proceedings of ICED 09, the 17th International Conference on Engineering Design, Vol. 4, Product and Systems Design, Palo Alto, CA, USA.2009.

12. Thomas, D.R.: A general inductive approach for analyzing qualitative evaluation data. American journal of evaluation 27(2), pp. 237-246 (2006).

13. Voss, C., Tsikriktsis, N., and Frohlich, M.: Case research in operations management. International journal of operations \& production management 22(2), pp. 195-219 (2002).

14. Eisenhardt, K.M.: Building theories from case study research. Academy of management review 14(4), pp. 532-550 (1989).

15. Miles, M.B., Huberman, A.M., and Saldana, J.: Qualitative data analysis. Sage (2013).

16. Fricke, E., Gebhard, B., Negele, H., and Igenbergs, E.: Coping with changes: causes, findings, and strategies. Systems Engineering 3(4), pp. 169-179 (2000). 